\title{
A fully coupled atmosphere-ocean wave modeling system for the Mediterranean Sea: interactions and sensitivity to the resolved scales and mechanisms
}

\author{
P. Katsafados ${ }^{1}$, A. Papadopoulos ${ }^{2}$, G. Korres ${ }^{3}$, and G. Varlas ${ }^{1,2}$ \\ ${ }^{1}$ Department of Geography, Harokopion University of Athens, 70 El. Venizelou Str., Athens, 17671, Greece \\ ${ }^{2}$ Institute of Marine Biological Resources and Inland Waters, Hellenic Centre for Marine Research, Anavyssos, Attiki, Greece \\ ${ }^{3}$ Institute of Oceanography, Hellenic Centre for Marine Research, Anavyssos, Attiki, Greece
}

Correspondence to: P. Katsafados (pkatsaf@hua.gr)

Received: 2 March 2015 - Published in Geosci. Model Dev. Discuss.: 27 May 2015

Revised: 14 December 2015 - Accepted: 15 December 2015 - Published: 21 January 2016

\begin{abstract}
It is commonly accepted that there is a need for a better understanding of the factors that contribute to air-sea interactions and their feedbacks. In this context it is important to develop advanced numerical prediction systems that treat the atmosphere and the ocean as a unified system. The realistic description and understanding of the exchange processes near the ocean surface requires knowledge of the sea state and its evolution. This can be achieved by considering the sea surface and the atmosphere as a continuously crosstalking dynamic system. Following and adapting concepts already developed and implemented in large-scale numerical weather models and in hurricane simulations, this study aims to present the effort towards developing a new, highresolution, two-way fully coupled atmosphere-ocean wave model in order to support both operational and research activities. A specific issue that is emphasized is the determination and parameterization of the air-sea momentum fluxes in conditions of extremely high and time-varying winds. Software considerations, data exchange as well as computational and scientific performance of the coupled system, the so-called WEW (worketa-wam), are also discussed. In a case study of a high-impact weather and sea-state event, the wind-wave parameterization scheme reduces the resulted wind speed and the significant wave height as a response to the increased aerodynamic drag over rough sea surfaces. Overall, WEW offers a more realistic representation of the momentum exchanges in the ocean wind-wave system and includes the effects of the resolved wave spectrum on the drag coefficient and its feedback on the momentum flux.
\end{abstract}

\section{Introduction}

There is a need for a better understanding of the factors that contribute to air-sea interaction mechanisms, and for the development of corresponding advanced prediction systems that treat the atmosphere and the sea as a unified system. The lack of consistent skill in present forecasting systems may be partially attributed to inadequate surface and boundarylayer formulations, and the lack of full coupling to a dynamic ocean (Chen et al., 2007). Sea waves play a key role in the exchange of momentum, heat, and turbulent kinetic energy at the air-sea interface. Wind waves, while being generated by the wind, extract energy and momentum from the atmosphere and therefore the drag that is felt by the atmosphere over the oceans becomes sea-state dependent. Furthermore, ocean waves affect the mixing of heat and momentum in the upper ocean layers.

For a better description and understanding of the exchange processes near the ocean surface, an accurate forecast of the evolution of the sea state requires considering the coupled sea surface and atmosphere as a continuously cross-talking system. Generally, at shorter and even more at longer scales, reliable results can be obtained by considering the fluid layer surrounding Earth as a single system. This means to simulate the atmosphere and the ocean as a single fully coupled system and to construct multi-model, multi-scale integrated systems (Liu et al., 2011).

The development of fully coupled simulation systems between atmosphere and ocean is the state of the art in the evolution of numerical weather prediction models. The com- 
plex mechanism of the exchange of momentum, mass, salt condensation nuclei, latent, and sensible heat between the atmosphere and the ocean has been improved by coupling the two systems. The large-scale perturbations in the general circulation of atmosphere and ocean, the temporal variability of dynamical air-sea interaction, and its feedbacks have already been incorporated into climate coupling systems (Battisti, 1988; Philander et al., 1992; Soden and Held, 2006; Roberts and Battisti, 2011). During the last several years, the importance of coupling at regional scales has challenged the research community (Hodur et al., 2002; Lionello et al., 2003). Due to the limited spatial and temporal interaction scales between atmosphere and ocean, the direct and sufficient response between the coupled models is a substantial factor (Warner et al., 2010).

Coupled atmosphere-ocean wave systems generally exchange near-surface wind velocity from the atmosphere to the surface wave and exchange friction velocity from the wave to the atmosphere. The modeling of the wave field allows for the introduction of a sea surface roughness feedback on the momentum flux (Lionello et al., 2003). Primarily, the change of the intensity of a storm or a cyclone due to the wave and the drag coefficient variability, under strong wind conditions is a critical field of study. More specifically, the hurricane force winds increase the drag coefficient magnitude of the sea surface that leads to a decrease of the wind speed and a change in the wind direction. Generally, the feedbacks ultimately create non-linear interactions between different components and make it difficult to assess the full impact on each specific model (Warner et al., 2010).

Various numerical experiments for 10 hurricane case studies in the western Atlantic Ocean during 1998-2003 were performed with an atmosphere-wave model (Moon et al., 2004), in which the drag coefficient used to approach the sea surface friction at different wave evolution stages was based on the relation proposed by Charnock (1955). As a result, in hurricane force wind conditions (above $33 \mathrm{~ms}^{-1}$ ), a positive forcing is observed from the decrease in sea surface friction arising from the coupling to the wave model. Additionally, the maximum friction velocity and sea surface roughness were much larger than their counterparts in an uncoupled system, with the largest sea surface roughness located in areas with small wave ages and wind speeds of $25-33 \mathrm{~m} \mathrm{~s}^{-1}$. For this reason, the cyclones that had been simulated by wind-wave coupled models developed more slowly than those simulated by non-coupled models. Also, maximum low-level wind speeds were typically underestimated by $2-3 \mathrm{~m} \mathrm{~s}^{-1}$ due to the feedback of ocean waveinduced stress. However, local differences in excess of $7-$ $10 \mathrm{~ms}^{-1}$ were found in some coupled model simulations (Doyle, 2002; Renault et al., 2012). In addition to these wind speed differences, significant wave height maxima were reduced by approximately $10 \%$ in the coupled simulations due to the enhanced roughness associated with the young ocean waves.
Following the abovementioned research, a number of centers and institutes worldwide have employed coupled systems for their upgraded operational activities. The European Centre for Medium-Range Weather Forecasts (ECMWF) is the pioneer in the development and implementation of coupling systems. ECMWF developed a coupled atmosphericocean wave model in order to be able to have two-way interaction, based on the quasi-linear theory of Janssen (1989, 1991). The ocean wave model of ECMWF (ECMWF WAM (wave model) or ECWAM) is fully coupled to the integrated forecasting system (IFS), which is the operational global meteorological forecasting model of the ECMWF (IFS Documentation, 2013; Diamantakis and Flemming, 2014). The ECWAM model software has been developed over a period of 10 years (1992 to 2002) for operationally predicting over the whole globe (Janssen, 2004). The ECWAM code was originally written for global-scale applications; however, it was extended to also run on smaller domains and in shallower water.

The United States Geological Survey (USGS) operates the coupled ocean-atmosphere-wave-sediment transport (COAWST) modeling system, which is integrated by the model coupling toolkit to exchange data fields between the ocean model ROMS (regional ocean modeling system), the atmosphere model WRF (weather research and forecasting model), the wave model SWAN (simulating waves nearshore), and the sediment capabilities developed as part of the Community Sediment Transport Modeling Project (Warner et al., 2010). The Earth system model (CNRMCM5, Centre National de Recherches M'etéorologiques Coupled Global Climate Model version 5) running operationally at Meteo-France consists of several existing models designed independently and coupled through the OASIS software (Redler et al., 2010). It includes the ARPEGE (Action de Recherche Petite Echelle Grande Echelle) model for the atmosphere, the NEMO (Nucleus for European Modelling of the Ocean) model for the ocean circulation, the GELATO (Global Experimental Leads and ice for ATmosphere and Ocean) model for sea-ice, the SURFEX (Surface Externalisée) model for land and the ocean-atmospheric fluxes, and the TRIP (total runoff integrating pathways) model to simulate river routing and water discharge from rivers to the ocean (Voldoire et al., 2012).

In a recent study three physical processes related to ocean surface waves, namely, the surface stress, the turbulent kinetic energy flux from breaking waves, and the StokesCoriolis force are incorporated in a general circulation ocean model (Breivik et al., 2015). Experiments are done with the NEMO model in ocean-only (forced) mode and coupled to the ECMWF atmospheric and wave models. Using oceanonly integrations and experiments with a coupled system consisting of the atmospheric model IFS, the wave model ECWAM, and NEMO, they demonstrated that the impact of the wave effects is particularly noticeable in the extratrop- 
ics. Of the three processes, the modification of the sea-statedependent turbulent kinetic energy has the largest impact.

In this context, this paper describes the strategy and approach adopted to develop a new, advanced, fully coupled atmosphere-ocean wave model for supporting the research and operational activities of the Hellenic Centre for Marine Research (HCMR) in the framework of the European Union (EU) funded MyWave project. A specific issue that is emphasized is the determination, parameterization, and the sensitivity of air-sea momentum fluxes in a case study involving extremely high and time-varying winds.

\section{Overview of modeling components of the coupled system}

The coupled system consists of two components: the atmospheric and the ocean wave models of the POSEIDON system. The atmospheric component is based on the Workstation Eta non-hydrostatic limited area model (Papadopoulos et al., 2002; Janjic, 2001; Nickovic et al., 2001; Mesinger et al., 1988). The ocean wave component is based on the fourth generation OpenMP (OMP) version of the WAM model (Monbaliu et al., 2000; Korres et al., 2011) and the resulting name of the coupled system is WEW.

\subsection{The atmospheric model}

The atmospheric model is based on an advanced version of the SKIRON/Eta mesoscale meteorological model, which is a modified version of the Eta/NCEP (National Centers for Environmental Prediction) model (Kallos et al., 1997; Nickovic et al., 2001; Papadopoulos et al., 2002). This version became the core of the second generation POSEIDON weather forecasting system (Papadopoulos and Katsafados, 2009) and is fully parallelized to run efficiently on any parallel computer platform. It uses a two-dimensional scheme for partitioning grid-point space to message-passing interface (MPI) tasks. MPI is a protocol for the data exchange and synchronization between the executing tasks of a parallel job.

The Eta model is designed to use either the hydrostatic approximation or the non-hydrostatic correction in order to be able to resolve high-resolution atmospheric processes. Eta is formulated as a grid-point model and the partial differential equations are represented by finite-difference schemes. The ETA model native grid is awkward to work with because the variables are on semi-staggered (e.g., the grid for wind is not the same as the grid for mass points) and nonrectangular (number of points in $x$ axis is not constant in respect to $y$ axis) grids. More specifically, in the horizontal dimension, the model is defined over the semi-staggered $E$ grid, as shown in Fig. 1.

The Eta model is well-documented and detailed descriptions of its dynamics and physics components can be found in several studies (e.g., Mesinger et al., 1988; Janjic, 1994;

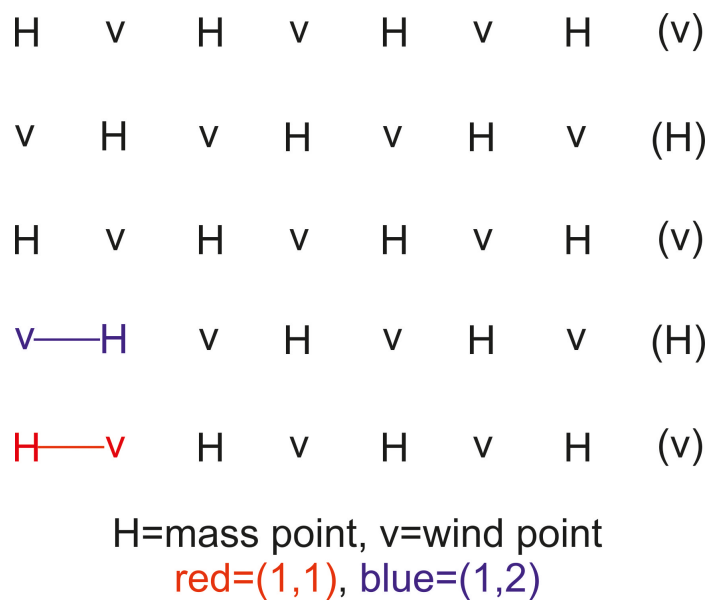

Figure 1. The E-grid stagger. The mass points represent by $H$ and the wind points represent by $v$.

Janjić et al., 2001, and references therein). The air-sea momentum fluxes are mainly parameterized in the surface layer scheme based on the well-established Monin-Obukhov similarity theory. It provides the lower boundary conditions for the 2.5 level turbulence model and introduces the viscous sublayer for a more realistic representation of the nearsurface fluxes. Different viscous sublayer approaches are applied over ground and over water surfaces in the model. For this specific application, special care was taken in the calculation of the $10 \mathrm{~m}$ wind. The calculations of the surface parameters within this viscous sublayer have an obvious advantage that decreases the level of uncertainty in the wind, air temperature, and humidity fields near the surface.

\subsection{The ocean wave model}

The wave forecasting system is based on WAM Cycle-4 code parallelized using only OMP directives. In order to reduce unrealistic energy loss at boundary points in cases where the waves propagate parallel and near the coast, the technique of Monbaliu et al. (2000) was applied wherein an alternative octant propagation coordinate system was introduced in the original WAM model code. For the octant advection scheme, eight propagation directions are defined instead of four in the classical quadrant scheme. Although in terms of computational workload, the octant scheme almost doubles the CPU time required by the upwind advection quadrant scheme, it has clear advantages over other conventional schemes, especially near the coastlines (Cavaleri and Sclavo, 1998).

The grid of the wave model for the Mediterranean and Black seas expands over the geographical area $8^{\circ} \mathrm{W}-42^{\circ} \mathrm{E}$ and $29-48^{\circ} \mathrm{N}$ as shown in Fig. 7 with a resolution of $1 / 20^{\circ} \times$ $1 / 20^{\circ}$. The bathymetric map has been constructed from Etopo2 data (National Geophysical Data Center, 2006; 2 min Gridded Global Relief Data (Etopo2) v2; National Geophysical Data Center, NOAA - National Oceanic and Atmospheric 
Administration) using bi-linear interpolation and some degree of smoothing. In shallow areas of the two basins, local corrections were introduced based on nautical charts issued by the Hellenic Navy Hydrographic Service.

The Mediterranean and Black seas wave model is a stand alone model since it has no open boundary towards the Atlantic basin. This is justified in the sense that no significant swell from the Atlantic Ocean is expected to propagate into the Mediterranean basin through the Strait of Gibraltar. The Dardanelles and Bosporus straits are also considered to be closed boundaries; thus, no wave energy is advected between Black Sea and Marmara Sea and between the Marmara Sea and the Aegean. The model uses 24 directional bins $\left(15^{\circ} \mathrm{di}-\right.$ rectional resolution) and 30 frequency bins (ranging between 0.05 and $0.793 \mathrm{~Hz}$ ) to represent the wave spectra distribution. The model runs in shallow water mode without depth or current refraction.

\section{The theoretical background}

In the offline coupled mode, the atmospheric model parameterizes the momentum exchange at the air-sea interface by applying a viscous sublayer scheme (Janjić, 1994), where the roughness $z_{0}$ over the sea surface is estimated by the formula

$z_{0}=\frac{a_{\mathrm{w}} \cdot u_{*}^{2}}{g}$,

assuming a constant Charnock coefficient $a_{\mathrm{w}}=0.018$ throughout the simulation. In turn, the wave model receives the near-surface wind components without providing any feedback to the atmosphere. Therefore, no interaction takes place between the two models.

In parallel, the WAM model considers a wind input source function to the wave spectrum equation based on the quasilinear theory of Janssen $(1989,1991)$, where the transfer of momentum from the wind to the wave field depends simultaneously on the wind stress and the sea state itself. Hence, the WAM model includes a set of diagnostic equations for modeling the sea surface roughness feedback on the near-surface atmospheric boundary layer (Janssen, 1989). The spatial and temporal variability of the Charnock coefficient is estimated at each WAM time step by

$a_{\mathrm{w}}=\frac{\hat{\alpha}}{\sqrt{1-\tau_{\mathrm{w}} / \tau}}$.

In the current WEW version $\hat{\alpha}$ is 0.01 but it has been adjusted to 0.006 in a recent ECWAM upgrade (IFS Documentation, 2013). In Eq. (2) $\tau_{\mathrm{W}}$ is the wave-induced stress given by

$\tau_{\mathrm{w}}=\rho_{\mathrm{w}} g \int \frac{k}{\omega} \cdot S_{\mathrm{in}} \cdot \mathrm{d} \omega \mathrm{d} \theta$

The wave-induced stress is mainly determined by the highfrequency part of the wave spectrum consisting of the waves that have the largest growth rate due to the wind. In Eq. (3) $\rho_{\mathrm{w}}$ is the density of sea water, $g$ is the gravitational acceleration, $S_{\text {in }}$ represents the wind input term in the wave model, $\omega$ is the angular frequency, $\theta$ is the propagation direction, and $\kappa$ is the wave number. The total stress $\tau$ is estimated as

$\tau=\rho_{\mathrm{a}} \cdot C_{\mathrm{D}} \cdot U_{\mathrm{ref}}^{2}$,

where $\rho_{\mathrm{a}}$ is the density of air, $U_{\text {ref }}$ is the wind speed at a reference height, and $C_{\mathrm{D}}$ is the drag coefficient equal to

$C_{\mathrm{D}}=\left(\frac{\kappa}{\log \left(z_{\mathrm{ref}} / z_{0}\right)}\right)^{2}$

with $\kappa$ being the von Karman constant. Combining Eqs. (4) and (5) the total stress is given by

$\tau=\left(\frac{\kappa \cdot U_{\mathrm{ref}}}{\log \left(z_{\mathrm{ref}} / z_{0}\right)}\right)^{2}$.

The estimated sea surface roughness length is

$z_{0}=\frac{0.01 \cdot \tau}{\rho_{\mathrm{a}} \cdot g \cdot \sqrt{1-\tau_{\mathrm{w}} / \tau}}$.

Finally, the computed friction velocity

$u_{*}=\sqrt{\tau / \rho_{\mathrm{a}}}$

is applied in the wind input source function $S_{\text {in }}$.

Therefore, in the fully coupled mode, WAM can provide the atmospheric model with consistent values of the Charnock coefficient, roughness, and the friction velocity at each time step. In the current version of WEW, the atmospheric model applies the variable Charnock parameter $a_{\mathrm{W}}$ in Eq. (1) for the estimation of the sea surface roughness length. According to the Mellor-Yamada-Janjic (MYJ) surface layer parameterization scheme (Janjić, 1994), a viscous sublayer is assumed over the oceans and operates under three sea-state regimes: (i) smooth and transitional, (ii) rough, and (iii) rough with spray, depending on the roughness Reynolds number and finally on the friction velocity, which is a monotonic function of $R_{\mathrm{r}}$ (Janjić, 1994)

$R_{\mathrm{r}}=\frac{z_{0} u_{*}}{v}$

where $v=1.5 \times 10^{-5} \mathrm{~m}^{2} \mathrm{~s}^{-1}$ is the kinematic viscosity of the air (Fig. 2). Then, the estimated friction velocity from WAM is applied for the determination of the sea-state regimes, instead of the friction velocity that is computed by the atmospheric model. In particular, the changes of the regimes have been set to $u_{* r}=0.3 \mathrm{~m} \mathrm{~s}^{-1}$ and $u_{* s}=0.7 \mathrm{~m} \mathrm{~s}^{-1}$.

The friction velocity of the atmospheric model is then estimated by

$u_{*}=\left[\left(\frac{K_{\mathrm{Msfc}}}{\Delta z_{\mathrm{e}}}\right)\left(U_{\mathrm{LM}}-U_{Z_{U}}\right)\right]^{1 / 2}$, 


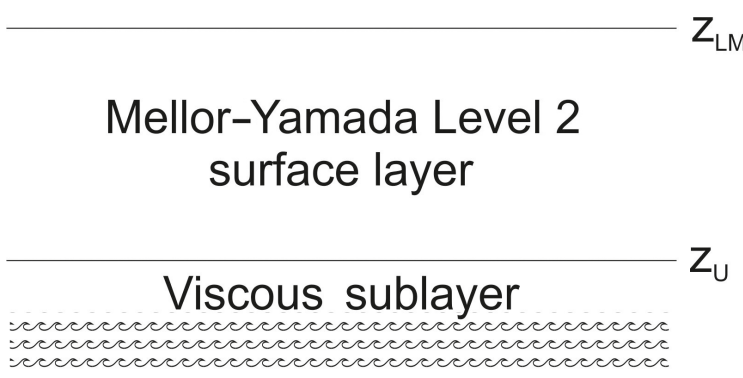

Figure 2. The Mellor-Yamada surface layer with the viscous sublayer over the ocean. The symbol $Z_{\mathrm{LM}}$ is the height of the lowest model layer and $Z_{U}$ is the depth of the viscous sublayer for momentum. (Reproduced from Janjić, 1994).

where $K_{\text {Msfc }}$ is the Mellor-Yamada level 2 discrete momentum exchange coefficient, $\Delta z_{\mathrm{e}}$ is the depth of the atmospheric layer that is extended between the lowest model level and the height of the dynamical turbulence layer at the bottom of the surface layer. The final term is the scalar difference between the wind velocity estimated at the lowest model level and the velocity at a height $z$ above the surface where the molecular diffusivities are still dominant (usually at the height of the viscous sublayer). The depth of the viscous sublayer for the momentum is estimated by

$z_{U}=\zeta \nu \frac{M\left(\frac{z_{0} u_{*}}{\nu}\right)^{1 / 4}}{u_{*}}$

where $\zeta=0.50$ and $M$ is depending on the sea-state regime. For smooth regime, $M=35$, and when the flow ceases to be smooth, $M=10$. The atmospheric roughness obtained from the Eq. (1) and the friction velocity from the Eq. (10) are then implemented for the estimation of the near-surface $\left(Z_{U 10}=\right.$ $\left.Z_{U}+10\right)$ wind components.

\section{Software considerations of the coupled system}

In the two-way coupled mode, the Eta and WAM models utilize different domain projections, integration time step, grid geometry, and cell size. Therefore, a major effort has been undertaken in order to homogenize and handle the data exchange between the atmospheric and the ocean wave components of the coupled system. These exchanges are built upon the MPI directives since it became a standard for developing parallel applications (Snir et al., 1998). Under the parallel environment of Multiple Program Multiple Data (MPMD), the two components are carried out as parallel tasks on different processors and they exchange information indirectly (Fig. 3). Thus, the parallel execution of the system is handled entirely by the mpirun/mpiexec commands and the two components maintain their own executables. The communication between the two models is performed using MPI_Send and MPI_Recv calls at every source time step of the ocean wave

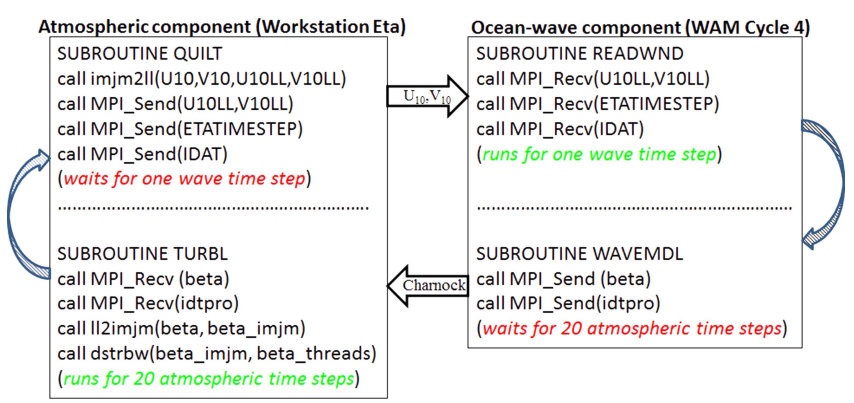

Figure 3. The WEW exchanges near-surface $U, V$ components, and Charnock coefficient every time step of the ocean wave model.

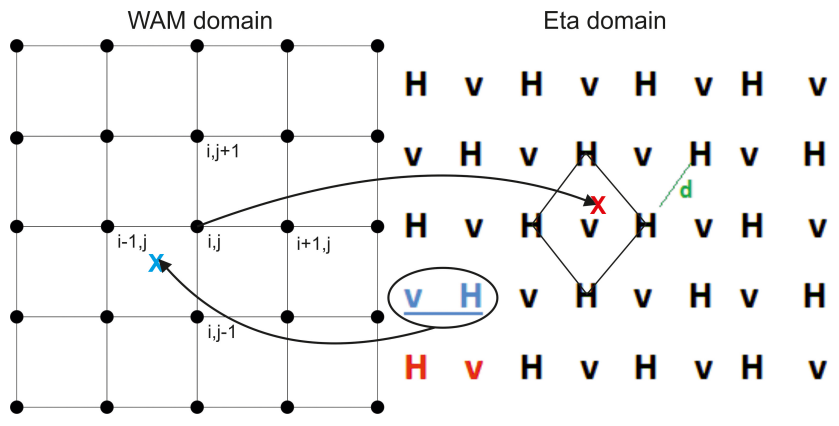

Figure 4. Sketch of the WEW multi-grid structure. The transformations from the Arakawa E grid to the regular lat-long grid and vice versa are also depicted.

model integration and the system runs flawlessly combining both MPICH and OMP environments. After the initial development, the modification of each component source code is relatively simple, just adding some data exchange routines and inserting the appropriate commands in the original model code, which call the coupling routines, while each component keeps its original structure.

At the initialization stage, the atmospheric model initializes and loads the inter- and intra-communicators. The atmospheric model sends the near-surface wind components to the wave model and receives the variable Charnock coefficient array, which is then used for the estimation of $z_{0}$ in the surface layer parameterization scheme. Each data exchange requires re-projection from the atmospheric model Arakawa E grid to the ocean wave model regular lat-long grid and vice versa (Fig. 4). For consistency, the sea-masks are exchanged at the initialization stage and the atmospheric to ocean wave time step ratio is set to $1 / 24$ but it can be adjusted to any other configuration through the main namelist of the system. Moreover, data exchanges can easily be expanded or eliminated and the ocean wave outputs (significant wave height and period, Charnock coefficient, friction velocity, etc.) are finally redirected through the internal communicators as outputs of the atmospheric component.

The initial version (v.0) of WEW was configured on a $2 \times 2$ topology (two additional processes are allocated for setting 


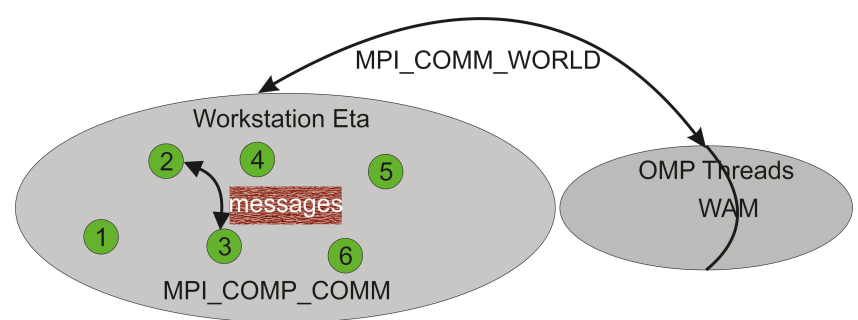

Figure 5. The WEW intra- and inter-communicators.

the I/O servers) for the atmospheric component (Fig. 5). The ocean wave component is parallelized using OMP directives and was configured with two threads. The current version (v.5) has been configured with a very fine horizontal resolution of $1 / 20^{\circ} \times 1 / 20^{\circ}$ with $493 \times 461 \mathrm{E}$-grid points and $1001 \times 381$ regular lat-long points. Numerous tests have been performed in order to extract the optimum topology. To this end, 28 threads have been allocated in total, 20 of which are dedicated to the execution of atmospheric component while the remaining eight are reserved for the ocean wave component. Thus, WEW is running on a Dual Quad core Intel Xeon platform cluster using 28 threads in total at four nodes, but it is easily portable to other architectures and flexible enough to adopt different topologies. For the abovementioned configuration, WEW requires almost $10 \mathrm{~min}$ for each simulation hour.

A multi-level flowchart of the system and the data exchanges are depicted in Fig. 6. In the offline coupling mode (CTRL hereafter), the atmospheric component sends hourly near-surface wind velocity to the ocean wave model without any other interaction between the two models (red line). In the two-way fully coupled mode (WEW hereafter), the atmospheric model sends the near-surface wind components at every WAM model time step and receives various near sea surface variables. In more details, for each time step WAM can provide the atmospheric model with consistent values of the Charnock coefficient, friction velocity, total surface stress, etc. In the current version, the atmospheric model ingests Charnock coefficient and friction velocity values into the Mellor-Yamada surface layer parameterization scheme for the estimation of the near-surface wind components for the next time step as well as the accurate determination of the viscous sublayer and the parameterization of the air-sea momentum fluxes.

\section{System configuration}

WEW has been configured on a domain encompassing the Mediterranean Sea and the Black Sea with a horizontal resolution of $0.05^{\circ} \times 0.05^{\circ}$ (Fig. 7). However, various tests of the system at the initial stages of the development were performed using a coarser grid of $0.10^{\circ} \times 0.10^{\circ}$. Gridded data from the ECMWF were used as initial and boundary condi-

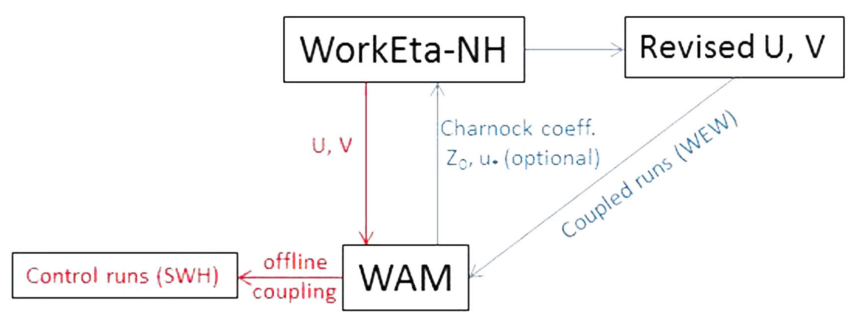

Figure 6. Informational flowchart for the offline coupled (red lines) and the two-way coupled simulations (blue lines).

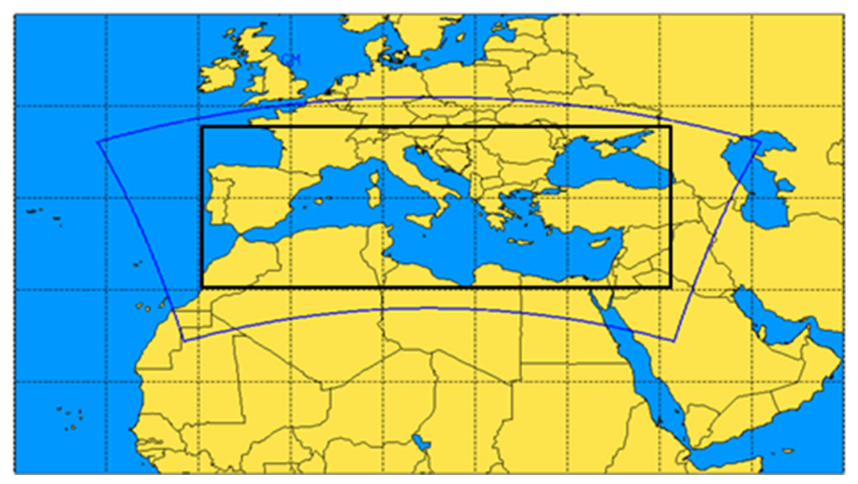

Figure 7. Current domain configurations of the atmospheric (blue line) and the ocean wave models (black line).

tions of the atmospheric component. The grid of the wave model for the Mediterranean and Black seas covers the geographical area $8^{\circ} \mathrm{W}-42^{\circ} \mathrm{E}$ and $29-48^{\circ} \mathrm{N}$ as shown in Fig. 7 (black line) using a resolution similar to that of the atmospheric component. The different projections of the two components yield a mismatch between the two domains. Thus, a constant Charnock coefficient $a_{\mathrm{w}}=0.018$ was implemented for the sea grid points of the atmospheric domain (near its western boundary), which were outside the WAM model domain. A 1-2-1 smoothing filter was also applied over the transition zone in order to reduce artificial-generated waves. The initialization of WAM was based on a wind-sea spectrum computed on the basis of the initial wind field and was produced during the preprocessing stage of the atmospheric model (cold start).

Each component of WEW maintained its own time step. The propagation time step of the WAM model was $120 \mathrm{~s}$ while its source time step was $360 \mathrm{~s}$. The coupling procedure exchanges data on the source time step of WAM model, $\mathrm{DT}_{\mathrm{w}}=360 \mathrm{~s}$. As the time step of the atmospheric model was $\mathrm{DT}_{\mathrm{a}}=15 \mathrm{~s}$, the exchange took place every 24 time steps of the atmospheric model. Every hour WEW stored its unified outputs (including atmospheric and ocean wave fields) on the native Arakawa E grid. The configuration of the system is summarized in Table 1. 
Table 1. The configuration of the WEW.

\begin{tabular}{lll}
\hline WEW version 5 & Atmospheric component & Ocean wave component \\
\hline Integration domain & \multicolumn{1}{c}{ Mediterranean Sea, Europe, Black Sea } \\
\hline Grid & $\begin{array}{l}\text { Arakawa semi-staggered E grid defined in } \\
\text { transformed lat-long coordinate system }\end{array}$ & Regular lat-long coordinate system \\
\hline Horizontal grid increment & & $0.05^{\circ} \times 0.05^{\circ}$ \\
\hline Spectral resolution & - & 24 directional bins $\left(15^{\circ}\right.$ directional resolution $)$, \\
& & 30 frequency bins $(0.05-0.793 \mathrm{~Hz})$ \\
\hline Vertical coordinate & Step mountain, $\eta$ coordinate & - \\
\hline Vertical levels & 38 & - \\
\hline Time steps (s) & 15 & $\begin{array}{l}\text { Propagation time step: } 120 \\
\text { Source time step: } 360\end{array}$ \\
\hline Initial\&boundary conditions & $\begin{array}{l}\text { ECMWF, } 0.5^{\circ} \times 0.5^{\circ}, 11 \text { isobaric levels, } 6 \mathrm{~h} \text { up- } \\
\text { date of the boundary conditions }\end{array}$ & $\begin{array}{l}\text { Initialization from the atmospheric component, } \\
\text { refresh rate every } 360 \mathrm{~s}\end{array}$ \\
\hline MPI/OMP topology & 16 MPI processing threads +4 I/O servers $=20$ & 8 OMP threads \\
\hline
\end{tabular}

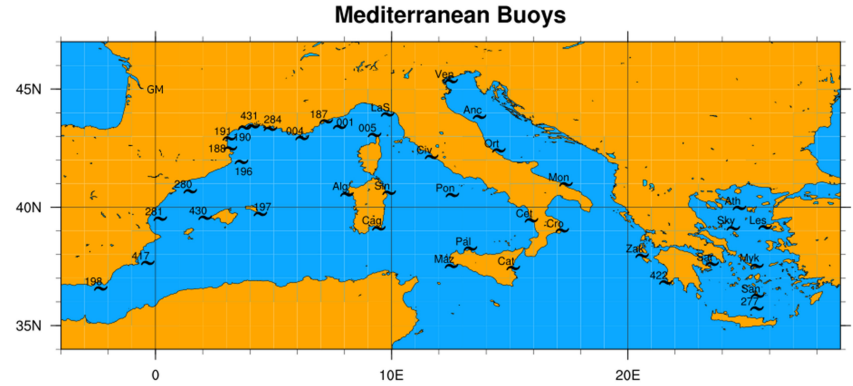

Figure 8. Spatial distribution of the Mediterranean buoys applied for the sensitivity test of the system. Data were made available from ISPRA in the framework of MyWave project.

\section{Application and performance of the WEW system}

WEW has been tested for its consistency and performance in a high-impact atmospheric and sea-state case study of an explosive cyclogenesis over the Ligurian Sea. The coupling efficiency was quantitatively estimated over sea areas using traditional statistical scores. Thus, the performance of the fully two-way coupled system (WEW) was compared against its performance in the CTRL based on a point-topoint comparison with in situ observations from a network of 39 buoys in the Mediterranean Sea (Fig. 8). The consistency of WEW was also assessed against remotely sensed data retrieved from CRYOSAT, ENVISAT and JASON1/2.

The incident of 4-11 January 2012 has been selected due to the severity of the prevailing atmospheric conditions characterized by an explosive cyclogenesis over the Ligurian Sea (Varlas et al., 2014). In more detail, on 5 January 2012 a low-pressure system formed over the cyclogenetic area of the
Ligurian Sea. It was mainly triggered by a widespread upperlevel trough extending from central Europe to the Mediterranean Sea (Fig. 9a). The upper-level trough rapidly intensified the system and supported its southeastern movement (Fig. 9b). On 6 January, the system moved toward the eastern Mediterranean, where the pressure dropped more than 1 Bergeron, satisfying the criteria for an explosive cyclogenesis event (Fig. 10a and b). Sanders and Gyakum (1980), defined an extratropical cyclone as a meteorological bomb when the mean sea-level pressure of its center falls by at least $1 \mathrm{hPa}$ per hour for $24 \mathrm{~h}$ at $60^{\circ} \mathrm{N}$. An equivalent rate is obtained for a latitude $\varphi$ by multiplying this rate by the dimensionless number $\sin \varphi / \sin 60^{\circ}$, which is denoted as 1 Bergeron (Katsafados et al., 2011). During 6 and 7 January, the strong pressure gradient provoked gale force winds and significant storm surge over a vast area, including the central Mediterranean and the Aegean Sea. It is worth noting that the buoys in the Ligurian and Balearic seas recorded wind speeds exceeding $20 \mathrm{~ms}^{-1}$ and significant wave height (SWH) over $5 \mathrm{~m}$.

The horizontal distributions of the wind speed and the SWH as well as their differences between WEW and the CTRL experiments are depicted in Fig. 11. On 6 January 2012 at 18:00 UTC, winds exceeding the $22 \mathrm{~ms}^{-1}$ and SWH over $8 \mathrm{~m}$ cover a large part of the Mediterranean Sea (Fig. 11a and b). The horizontal distribution of differences between WEW and the CTRL experiments reveals a systematic reduction of the wind speed and the SWH in the two-way fully coupled mode (WEW). The near-surface wind speed differences vary up to $2 \mathrm{~ms}^{-1}$ and are located over the areas where maximum wind velocities occurred (Fig. 11c). The reduced wind speed simulated by WEW, as a feedback of the enhanced sea surface roughness, impacts the estimated SWH 


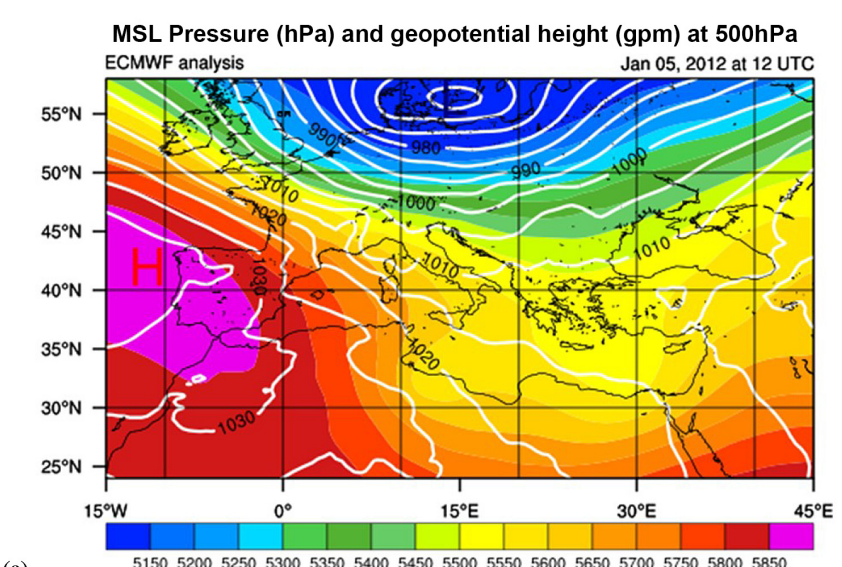

(a)

515052005250530053505400545055005550560056505700575058005850

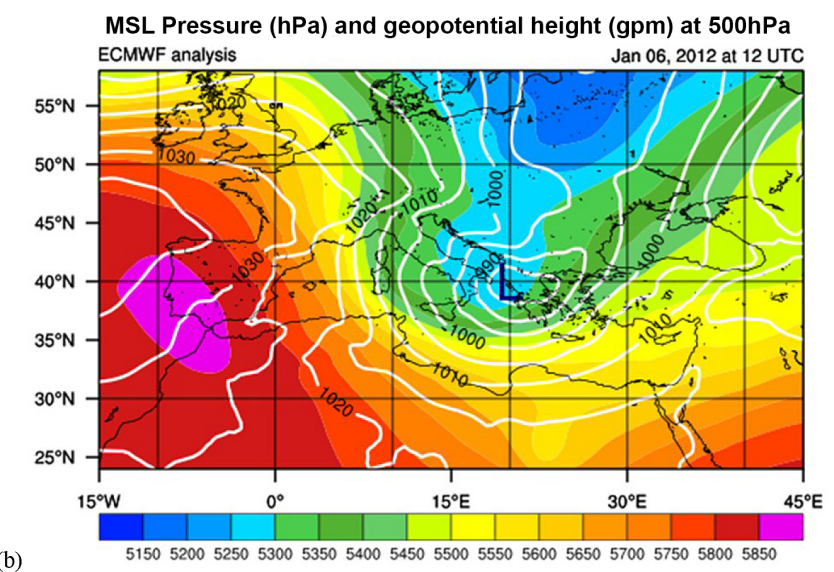

Figure 9. Mean sea level pressure (contours in $\mathrm{hPa}$ ) and geopotential height at $500 \mathrm{hPa}$ (colored shaded in gpm) for (a) 5 January at 12:00 UTC, and (b) 6 January at 12:00 UTC 2012. Data are based on ECMWF operational analysis.

as well (Fig. 11d). Thus, SWH differences up to $1.2 \mathrm{~m}$ occur over the areas of the maximum wind speed reduction (e.g., the area between the Balearic and Tyrrhenian seas). Similar results have been also observed by Doyle (2002), Janssen (2004), Liu et al. (2011), and Renault et al. (2012).

The outputs from both simulations, CTRL and WEW, have been statistically assessed based on a point-to-point hourly comparison between model-generated variables and the available Mediterranean buoy measurements. Hourly pairs of observed and estimated values were obtained using the nearest-neighbor interpolation technique, taking care of whether this nearest source point is a sea masked grid point. Despite the known problems of the issues associated with comparing point measurements with area-averaged predictions, the in situ measurements from the buoy network are valuable in providing wind data for comparing the error statistics between the uncoupled and coupled simulations. Figure 12 summarizes the main statistical scores for both simulations. As indicated in Fig. 12a both simulations slightly underestimate the near-surface wind speed (nega-
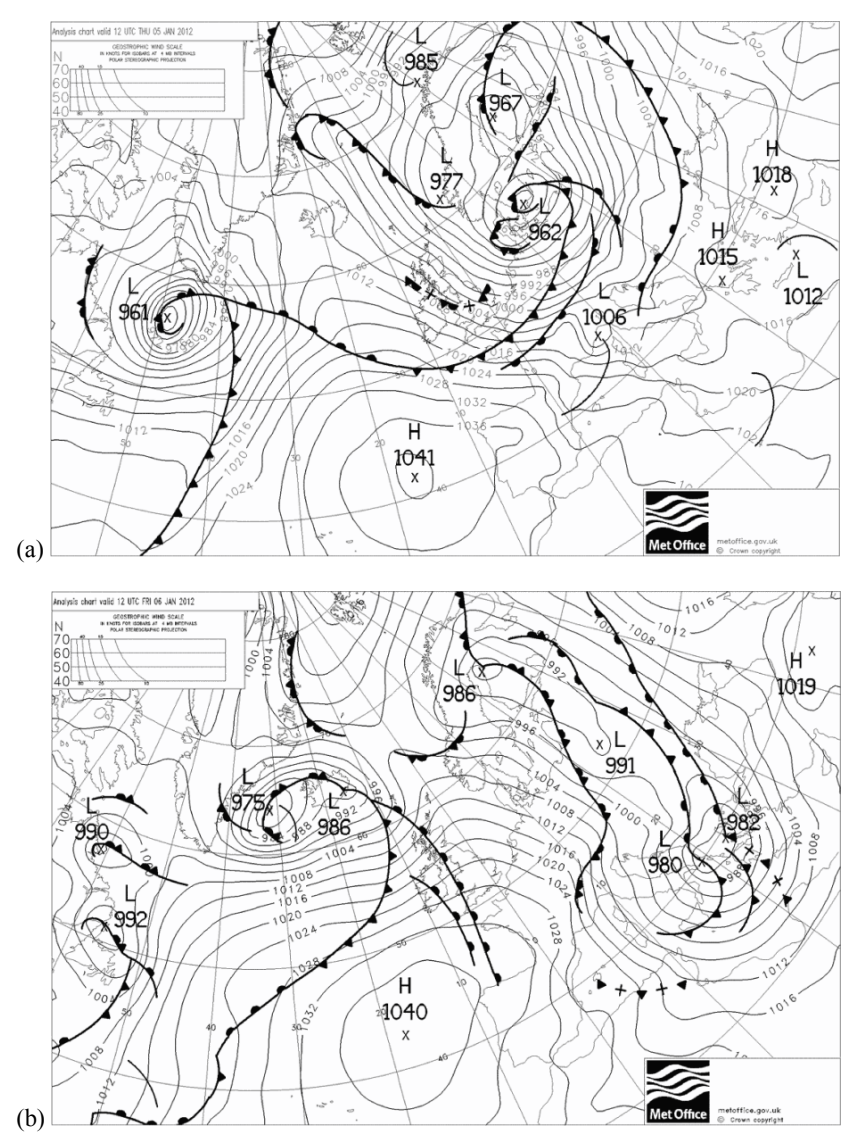

Figure 10. Surface pressure analysis map (mb) for (a) 5 January at 12:00 UTC (b) 6 January at 12:00 UTC, 2012. The maps derived from UK Met office surface analysis archive.

tive bias scores). Although the CTRL gives less biased wind speed estimation than WEW, the latter exhibits a slight improvement of the RMSE (root mean square error) by approximately $2 \%$. Additionally, WEW reduces the standard deviation of the model towards that of the buoy's measurements. In accordance with the wind speed, the bias scores of the SWH indicate an underestimation, which is more prominent in the WEW simulation (Fig. 12b). However, WEW exhibits an overall improvement of more than $7 \%$ regarding the SWH RMSE, with 0.53 instead of $0.57 \mathrm{~m}$, and better correlation coefficients.

The respective error properties are quite similar in the open sea. Comparison with the remotely sensed data referenced in this section showed that WEW has slightly better statistics (e.g., lower RMSE) than CTRL, despite the fact that it seems to enhance the underestimation of the wind speed and the SWH. In particular, Fig. 12c indicates that WEW tends to increase the underestimation of the wind speed already present in the CTRL, reducing the respective RMSE by $1.5 \%$ at the same time. Also, Fig. 12d shows that the RMSE is smaller for WEW SWH values compared to CTRL values by almost $11 \%$, in contrast to the slight overestimation of 

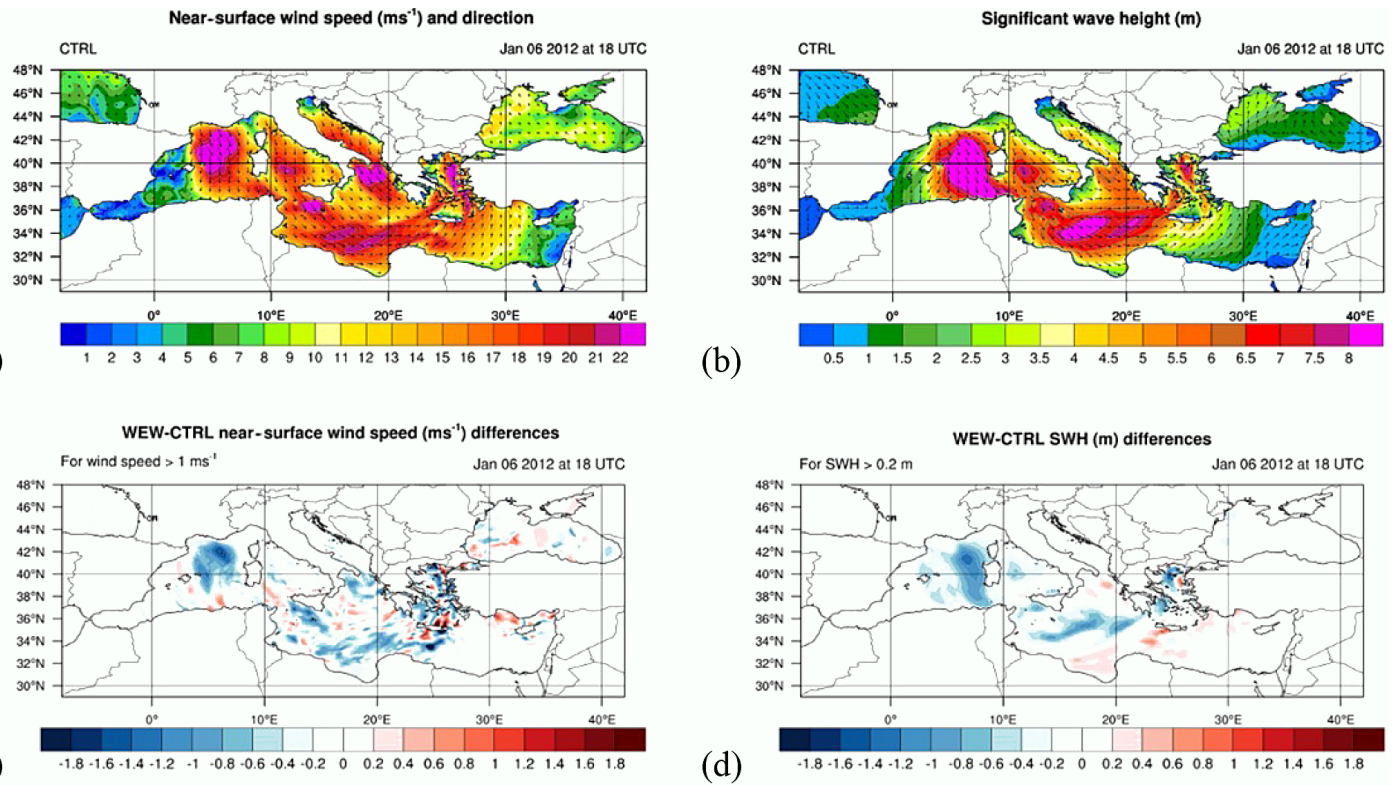

Figure 11. Panel of the horizontal distribution for the (a) wind speed, (b) SWH, and their differences between WEW and CTRL experiments for the (c) wind speed and (d) SWH for 6 January 2012 at 18:00 UTC.
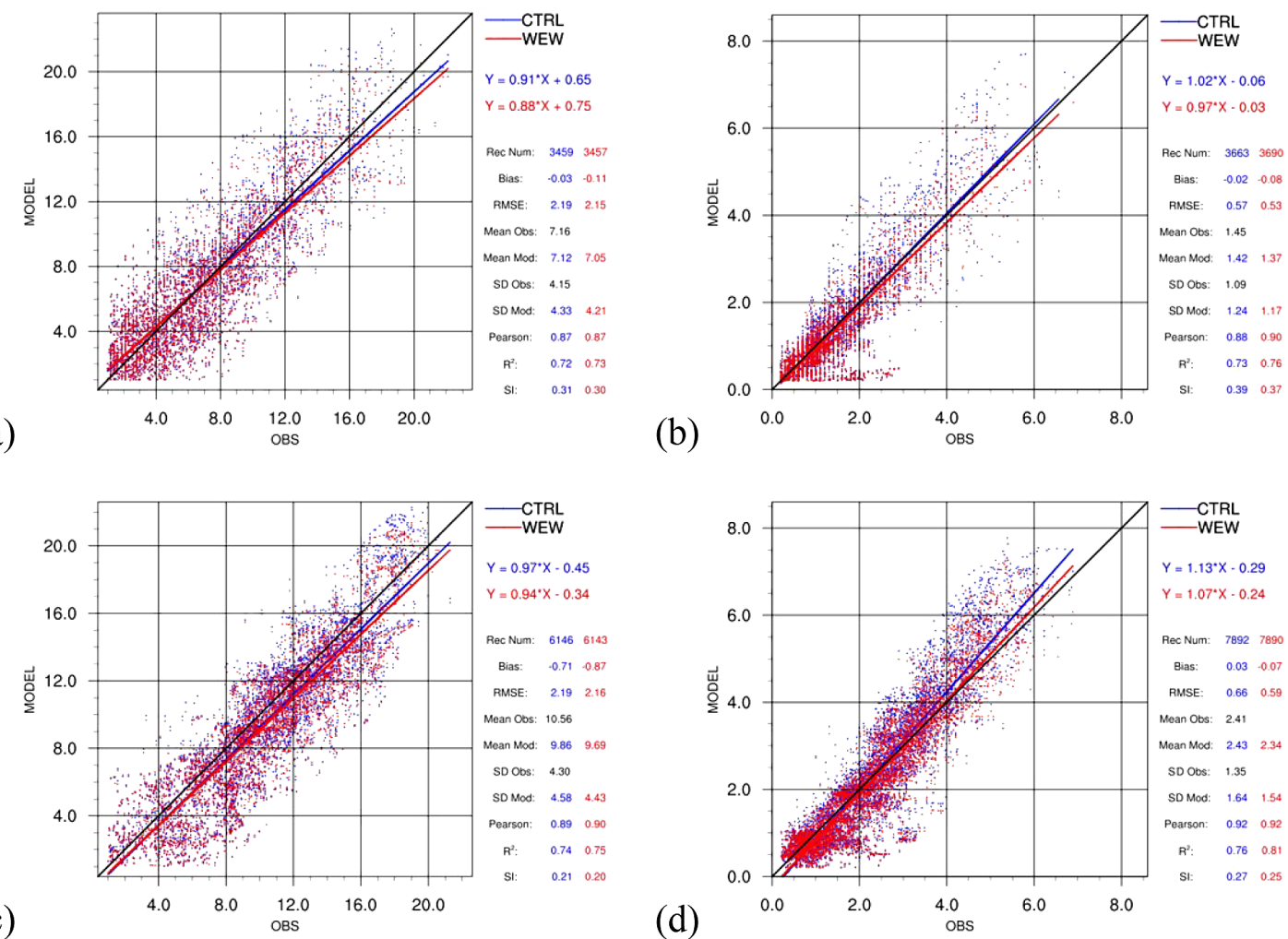

Figure 12. Scatter plots of the near-surface wind speed exceeding $1 \mathrm{~ms}^{-1}(\mathbf{a}, \mathbf{c})$ and the significant wave height exceeding $0.2 \mathrm{~m}(\mathbf{b}, \mathbf{d})$ against the network of the Mediterranean buoys (a, b) and the remotely sensed retrievals (c, d) for the period 4-11 January 2012. $y$ axis presents the model-estimated values and $x$ axis the buoys observations $(\mathbf{a}, \mathbf{b})$ and the satellite estimations $(\mathbf{c}, \mathbf{d})$. CTRL and WEW evaluation results are shown in blue and red colors, respectively. 
the CTRL SWH and the slight underestimation of the SWH occurring in WEW. The error statistics are significant at the $95 \%$ confidence level. Although WEW increases the wind and the SWH underestimation, it overall improves the SWH RMSE by approximately $7 \%$ against buoys data and by $11 \%$ against remotely sensed data. In contrast to the bias scores, RMSE penalizes the variance between in situ or remotely sensed data and the simulations implying a deterioration of the RMSE in CTRL run (Chai and Draxler, 2014). Similar RMSE improvements by the coupled systems have been also confirmed in the relevant literature (e.g., Lionello et al., 2003; Renault et al., 2012). Moreover, in a parallel to WEW research effort within the MyWave project the Italian team consisting of the Institute of Marine Sciences (ISMAR) and the Italian Meteorological Service (CNMCA) coupled WAM with the COSMO (Consortium for Small-scale Modeling) atmospheric model over the Mediterranean Sea (at a lower horizontal resolution though) showing similar results especially in terms of winds and significant wave height RMSE reduction (Torrisi et al., 2014). Overall, WEW offers a more realistic representation of the air-sea interaction processes although it is not reflected in an exceptional improvement of the statistical scores. This is attributed to the fact that the application of the two-way fully coupled system can generate and support a more realistic near sea surface atmospheric circulation pattern by fully resolving air-sea interaction mechanisms at the relevant interface, including the wind speed regime and wave patterns.

\subsection{Physical interpretation}

The particular interactions considered in WEW are mainly driven by the momentum exchanges in the ocean windwave system. The fully coupled wind-wave parameterization scheme includes the effects of the resolved wave spectrum on the drag coefficient and its feedback on the momentum flux. In general, the feedbacks create non-linear interactions in the dynamic structure of a storm or a cyclone due to the timespace sea surface friction variability. In WEW simulations, the maximum friction velocity and sea surface roughness are much larger than their counterparts in CTRL, with the maxima located in areas with small wave ages and wind speeds above $20 \mathrm{~ms}^{-1}$. The increased near sea surface friction builds a more turbulent and deeper PBL, preventing faster evolution of the storm (Fig. 13).

The reduction of the near-surface wind speed, as was evident in the WEW simulation and depicted in Fig. 11c, is mainly attributed to the variable Charnock coefficient directly ingested in Eq. (1) for the roughness length estimation in the MYJ surface layer parameterization scheme. In the CTRL and WEW experiments, the Charnock coefficient logarithmically increases with wind speed at approximately $22 \mathrm{~ms}^{-1}$ (Fig. 14). The enhanced Charnock coefficient increases the roughness length and decreases the near-surface wind speed in WEW simulations. This also affects the es-

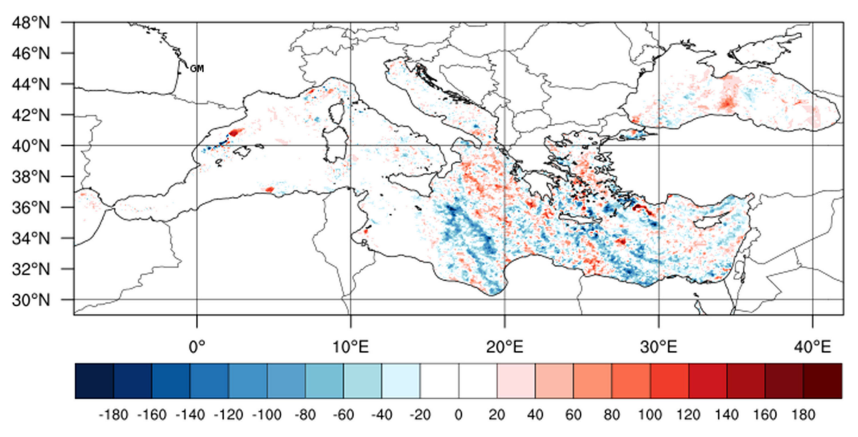

Figure 13. Spatial distribution of the averaged PBL height (in $\mathrm{m}$ ) difference (WEW - CTRL) for the period 6-7 January 2012.

timation of the significant wave height in the two-way coupled simulations. Especially in WEW (Fig. 14b), a doubtful saturation of the Charnock coefficient for wind speeds exceeding $22 \mathrm{~ms}^{-1}$ is particularly noticeable indicating that in extremely high-wind conditions, the sea surface friction is preserved or even decreases, offering a positive forcing to the flow. Although this mechanism is described in Donelan et al. (2004), the WAM model does not resolve processes such as flow separation or wave breaking under extremely high-wind conditions. The saturation of the Charnock coefficient may be attributed to the wind prevails in very young sea states and short fetches, which are unable to carry the full stress that a slightly more mature sea state can (Bidlot, 2012). Moreover, the apparent increase in Charnock around winds of $6 \mathrm{~ms}^{-1}$ may be explained by the lack of frequency resolution in the spectrum at high frequency because of the logarithmic frequency spacing and the choice of cut-off frequency. Although the wind-wave parameterization feature offers a realistic representation of the aerodynamic drag over rough sea surfaces, the saturation of the Charnock coefficient has to be confirmed in more case studies involving a number of synoptic to mesoscale storms on even higher wind regimes.

The roughness length as a function of the friction velocity is characterized by an initial decrease as the surface condition goes from an aerodynamically smooth to an aerodynamically rougher regime (Fig. 15). This is the result of an aerodynamically smooth surface where the molecular motions are dominant in the developed viscous sublayer (Csanady, 2001). In moderate and fully rough sea-state regimes, the roughness length is exponentially increasing with the friction velocity. The roughness length in WEW is substantially larger than in CTRL for friction velocities exceeding $0.60 \mathrm{~ms}^{-1}$. This is an indication of the enhanced friction in WEW under rough seastate regimes as a result of the variable Charnock parameter in the surface layer parameterization scheme. 

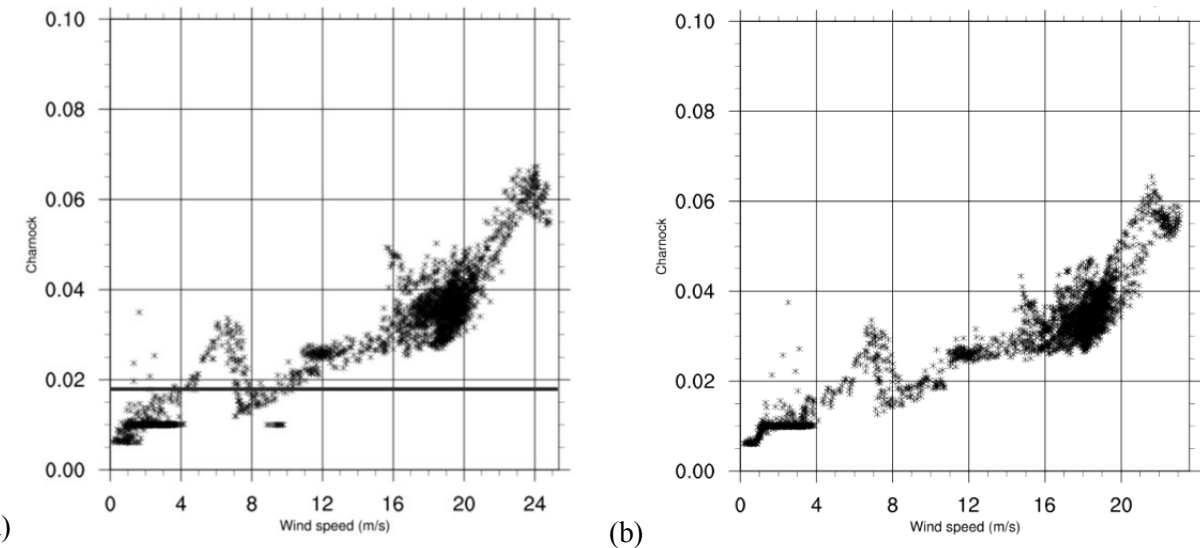

Figure 14. Charnock coefficient dependence to the wind speed in (a) offline coupled simulations. The thick solid line indicates the constant Charnock value (0.018) in the MYJ surface layer parameterization scheme. (b) WEW simulations. The diagrams consist of selected sea points with severe winds during the period 4-11 January 2012.
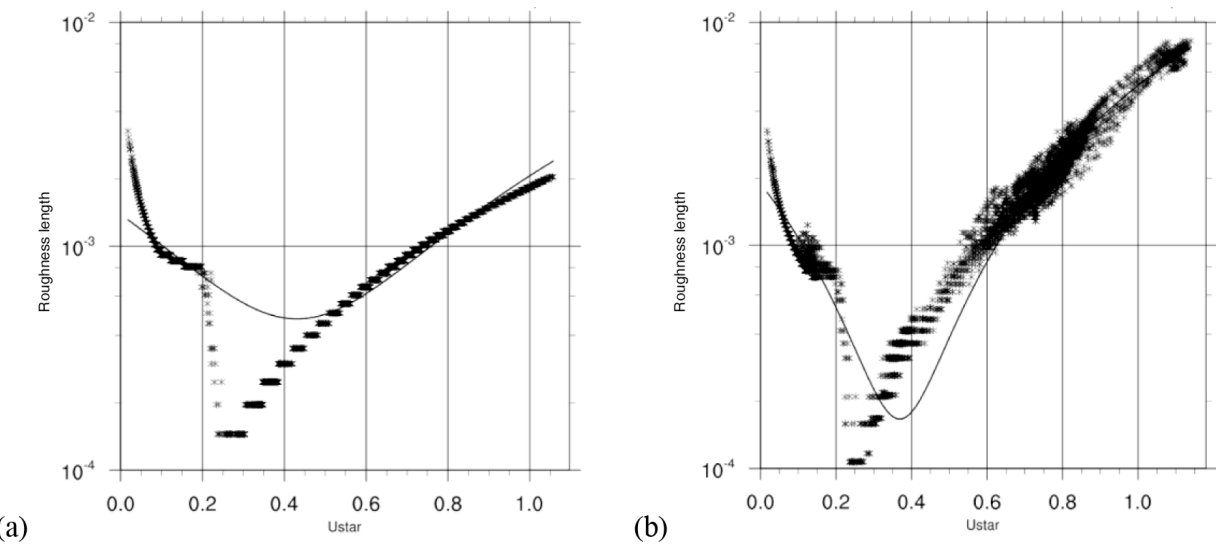

Figure 15. Roughness length $(\mathrm{m})$ dependence to the friction velocity $\left(\mathrm{ms}^{-1}\right)$ for (a) the CTRL and (b) WEW experiments. The diagrams consist of selected sea points with severe winds during the period 4-11 January 2012. The solid lines stand for the polynomial curve fitting to the data.

\section{Concluding remarks and future perspectives}

WEW is the recently developed two-way fully coupled atmosphere-ocean wave system designed to support air-sea interaction research and operational activities at HCMR. This new coupled system has made it possible for the atmospheric model to ingest a physically based momentum roughness length based on sea state. The system is built in the MPMD environment where the atmospheric and the ocean wave components are handled as parallel tasks on different processors. In the offline coupled mode, the atmospheric component parameterizes the air-sea momentum by estimating the roughness length over the sea surface as a function of a constant Charnock coefficient throughout the simulation. The ocean wave component passively receives the near-surface wind components and there is no interaction between the two models. In WEW, the atmospheric model sends the nearsurface wind components to the wave model on its time step frequency and receives the space-time variable Charnock field, which is directly applied in the surface layer parameterization scheme for the estimation of the roughness length.

Interactions considered in WEW are mainly driven by the momentum exchanges in the ocean wind-wave system and include the effects of the resolved wave spectrum on the drag coefficient and its feedback on the momentum flux. As a general outcome, the maximum friction velocity and sea surface roughness are much larger than their counterparts in the offline coupled mode, which resulted in a more turbulent and deeper marine PBL. The reduction of the near-surface wind speed in the fully coupled simulation is mainly attributed to the enhanced Charnock coefficient, which increases the roughness length and finally decreases the SWH. The Charnock coefficient logarithmically increases with wind speed at approximately $22 \mathrm{~ms}^{-1}$ and the saturation above indicates that in extremely high-wind conditions the sea surface friction is preserved or even decreases, 
resulting a positive forcing to the flow. This wind-wave parameterization feature offers a more realistic representation of the aerodynamic drag over rough sea surfaces (Chen et al., 2007).

This aspect was tested in a high-impact atmospheric and sea-state case study of an explosive cyclogenesis in the Mediterranean Sea. Despite the increased underestimation, affecting both wind speed and significant wave height, WEW offers an overall improvement in their RMSE up to $11 \%$. The underestimation is attributed to the direct implementation of the variable Charnock coefficient in the current surface layer parameterization scheme and is more prominent at gale force wind speeds. Therefore, an extended modification of the current MYJ scheme is recommended, and it is in the authors' future plan, in order to adjust it to the updated sea surface forcing dynamically obtained from the ocean wave component. To this end, an alternative parameterization scheme is under development for the more realistic representation of the sea surface momentum exchange and its feedbacks in WEW.

\section{Code availability}

For ETA model and WAM model users, the relevant code modifications for coupling the two numerical systems can be made available by Petros Katsafados (pkatsaf@hua.gr), Anastasios Papadopoulos (tpapa@hcmr.gr), and Gerasimos Korres (gkorres@hcmr.gr).

Acknowledgements. This research is supported by the EU-funded project MyWave (FP7-SPACE-2011-1/CP-FP, SPA.2011.1.5-03). ISPRA and IFREMER (Globwave project) are gratefully acknowledged for the provision of buoy and satellite data, respectively. ECMWF is acknowledged for the kind provision of the gridded analyses data. The authors are also grateful to the editor A. Yool for his feedback concerning the improvement of the manuscript.

Edited by: A. Yool

\section{References}

Battisti, D. S.: Dynamics and thermodynamics of a warming event in a coupled tropical atmosphere-ocean model, J. Atmos. Sci., 45, 2889-2919, 1988.

Bidlot, J. R.: Present status of wave forecasting at ECMWF. Proceeding from the ECMWF Workshop on Ocean Waves, 25-27 June 2012, ECMWF, Reading, United Kingdom, 2012.

Breivik, Ø., Mogensen, K., Bidlot, J.-R., Balmaseda, M. A., and Janssen, P. A. E. M.: Surface wave effects in the NEMO ocean model: Forced and coupled experiments, J. Geophys. Res. Ocean., 120, 2973-2992, doi:10.1002/2014JC010565.

Cavaleri, L. and Sclavo, M.: Characteristics of quadrant and octant advection schemes in wave models, Coastal Eng., 34, 221-242, 1998.
Chai, T. and Draxler, R. R.: Root mean square error (RMSE) or mean absolute error (MAE)? - Arguments against avoiding RMSE in the literature, Geosci. Model Dev., 7, 1247-1250, doi:10.5194/gmd-7-1247-2014, 2014.

Charnock, H.: Wind stress on a water surface, Q. J. Roy. Meteor. Soc., 81, 639-640, 1955.

Chen, S. S., Zhao, W., Donelan, M. A., Price, J. F., and Walsh, E. J.: The CBLAST-Hurricane Program and the Next-Generation Fully Coupled Atmosphere-Wave-Ocean Models for Hurricane Research and Prediction, B. Am. Meteorol. Soc., 88, 311-317, 2007.

Csanady, G. T.: Air-sea interaction: Laws and mechanisms, Cambridge University Press, ISBN 0521796806, 249 pp., 2001.

Diamantakis, M. and Flemming, J.: Global mass fixer algorithms for conservative tracer transport in the ECMWF model, Geosci. Model Dev., 7, 965-979, doi:10.5194/gmd-7-965-2014, 2014.

Donelan, M. A., Haus, B. K., Reul, N., Plant, W. J., Stiassnie, M., Graber, H. C., Brown, O. B., and Saltzman, E. S.: On the limiting aerodynamic roughness of the ocean in very strong winds, Geophys. Res. Lett., 31, 4539-4542, 2004.

Doyle, J. D.: Coupled atmosphere-ocean wave simulations under high wind conditions, Mon. Weather Rev., 130, 3087-3099, 2002.

Hodur, R. M., Pullen, J., Cummings, J., Hong, X., Doyle, J. D., Martin, P., and Rennick, M. A.: The Coupled Ocean/Atmosphere Mesoscale Prediction System (COAMPS), Oceanography, 15, 88-98, 2002.

IFS Documentation, Part VII: ECMWF wave model, 2013, available at: http://old.ecmwf.int/research/ifsdocs/CY40r1/, last access: 19 August 2015.

Janjić, Z. I.: The step-mountain eta coordinate model: further developments of the convection, viscous sublayer, and turbulence closure schemes, Mon. Weather Rev., 122, 927-945, 1994.

Janjic, Z. I., Gerrity, Jr., J. P., and Nickovic, S.: An Alternative Approach to Nonhydrostatic Modeling, Mon. Weather Rev., 129, 1164-1178, 2001.

Janssen, P. A. E. M.: Wave-induced stress and the drag of air flow over sea waves, J. Phys. Oceanogr., 19, 745-754, 1989.

Janssen, P. A. E. M.: Quasi-linear theory of wind-wave generation applied to wave forecasting, J. Phys. Oceanogr., 21, 1631-1642, 1991.

Janssen, P. A. E. M.: The interaction of ocean waves and wind, Cambridge University Press, ISBN 9780521121040, 385 pp., 2004.

Kallos, G., Nickovic, S., Papadopoulos, A., Jovic, D., Kakaliagou, O., Misirlis, N., Boukas, L., Mimikou, N., Sakellaridis, G., Papageorgiou, J., Anadranistakis, E., and Manousakis, M.: The regional weather forecasting system SKIRON: An overview, in: Proceedings of the Symposium on Regional Weather Prediction on Parallel Computer Environments, Athens, Greece, 15-17 October 1997, 109-122, 1997.

Katsafados, P., Mavromatidis, E., Papadopoulos, A., and Pytharoulis, I.: Numerical simulation of a deep Mediterranean storm and its sensitivity on sea surface temperature, Nat. Hazards Earth Syst. Sci., 11, 1233-1246, doi:10.5194/nhess-111233-2011, 2011.

Korres, G., Papadopoulos, A., Katsafados, P., Ballas, D., Perivoliotis, L., and Nittis, K.: A 2-year intercomparison of the WAMCycle4 and the WAVEWATCH-III wave models implemented 
within the Mediterranean Sea, Mediterranean Marine Science, 12, 129-152, 2011.

Lionello, P., Martucci, G., and Zampieri, M.: Implementation of a Coupled Atmosphere-Wave-Ocean Model in the Mediterranean Sea: Sensitivity of the Short Time Scale Evolution to the Air-Sea Coupling Mechanisms, Global Atmosphere and Ocean System, 9, 65-95, 2003

Liu, B., Liu, H., Xie, L., Guan, C., and Zhao, D.: A Coupled Atmosphere-Wave-Ocean Modeling System: Simulation of the Intensity of an Idealized Tropical Cyclone, Mon. Weather Rev., 139, 132-152, 2011.

Mesinger, F., Janjic, Z. I., Nickovic, S., Gavrilov, D., and Deaven, D. G.: The step-mountain coordinate: Model description and performance for cases of Alpine lee cyclogenesis and for a case of an Appalachian redevelopment, Mon. Weather Rev., 116, 14931518,1988

Monbaliu, J., Hargreaves, R., Albiach, J., Luo, W., Sclavo, M., and Günther, H.: The spectral wave model, WAM, adapted for applications with high spatial resolution, Coast. Eng., 41, 41-62, 2000.

Moon, I., Ginis, I., and Hara, T.: Effect of surface waves on Charnock coefficient under tropical cyclones, Geophys. Res. Lett., 31, L20302, doi:10.1029/2004GL020988, 2004.

Nickovic, S., Kallos, G., Papadopoulos, A., and Kakaliagou, O.: A model for prediction of desert dust cycle in the atmosphere, J. Geophophys. Res., 106, 18113-18129, 2001.

Papadopoulos, A. and Katsafados, P.: Verification of operational weather forecasts from the POSEIDON system across the Eastern Mediterranean, Nat. Hazards Earth Syst. Sci., 9, 1299-1306, doi:10.5194/nhess-9-1299-2009, 2009.

Papadopoulos, A., Katsafados, P., Kallos, G., and Nickovic, S.: The weather forecasting system for POSEIDON-An overview, Global Atmosphere and Ocean System, 8, 219-237, 2002.

Philander, S. G. H., Pacanowski, R. C., Lau, N. C., and Nath, M. J.: Simulation of ENSO with a global atmospheric GCM coupled to a high-resolution, tropical Pacific Ocean GCM, J. Climate, 5, 308-329, 1992.

Redler, R., Valcke, S., and Ritzdorf, H.: OASIS4 - a coupling software for next generation earth system modelling, Geosci. Model Dev., 3, 87-104, doi:10.5194/gmd-3-87-2010, 2010.
Renault, L., Chiggiato, J., Warner, J. C., Gomez, M., Vizoso, G., and Tintoré, J.: Coupled atmosphere-ocean-wave simulations of a storm event over the Gulf of Lion and Balearic Sea, J. Geophys. Res., 117(C09019), 2012.

Roberts, W. H. and Battisti, D. S.: A new tool for evaluating the physics of coupled atmosphere-ocean variability in nature and in general circulation models, Clim. Dynam., 36, 907-923, 2011.

Sanders, F. and Gyakum, J. R.: Synoptic-dynamic climatology of the bomb, Mon. Weather Rev., 108, 1589-1606, 1980.

Soden, B. J. and Held, I. M.: An assessment of climate feedbacks in coupled ocean-atmosphere models, J. Climate, 19, 3354-3360, 2006.

Snir M., Otto, S., Huss-Lederman, S., Walker, D., and Dongarra, J.: MPI-The complete reference. ISBN 0-262-69215-5, Massachusetts Institute of Technology, 1998.

Torrisi L., Cavaleri L., Korres G., Papadopoulos A., Varlas G., and Katsafados P.: Report on Wave Coupling, My Wave EU funded project, D-1.4, 63 pp., 2014.

Varlas, G., Papadopoulos, A., Korres, G., and Katsafados, P.: Modeling the air-sea wave interaction processes in an explosive cyclone over the Mediterranean Sea, 12th International Conference on Meteorology, Climatology and Atmospheric Physics (COMECAP 2014), University of Crete, Heraklion, Crete, Greece, 28-31 May 2014, Vol. 3, 289-294, 2014.

Voldoire, A., Sanchez-Gomez, E., Salas y Mélia, D., Decharme, B., Cassou, C., Sénési, S., Valcke, S., Beau, I., Alias, A., Chevallier, M., Déqué, M., Deshayes, J., Douville, E. Fernandez, G. Madec, E. Maisonnave, M.-P. Moine, S. Planton, D.Saint-Martin, H., Szopa, S., Tyteca, S., Alkama, R., Belamari, S., Braun, A., Coquart, L., and Chauvin, F.: The CNRM-CM5.1 global climate model: description and basic evaluation, Clim. Dynam., 40, 2091-2121, 2012.

Warner, J. C., Armstrong, B., He, R., and Zambon, J. B.: Development of a coupled ocean-atmosphere-wave-sediment transport (COAWST) modeling system, Ocean Model., 35, 230-244, 2010 . 